\title{
Large Bilateral Symptomatic Pelvic Lymphoceles Following a Radical Prostatectomy
}

"Philips G. Michael, Rakesh Jamkhandikar, Girish L. Kukade, Said K. S. Al-Aghbari

$$
\text { قيلة لمفية حوضية أعراضية ثنائية الجانب وكبيرة عقب استئصال بحُّرِيَّ للبروستاتة }
$$$$
\text { فيليبس ميشيل، راكيش جامخانديكار، جايرش كوكادي، سعيد الأغبري }
$$
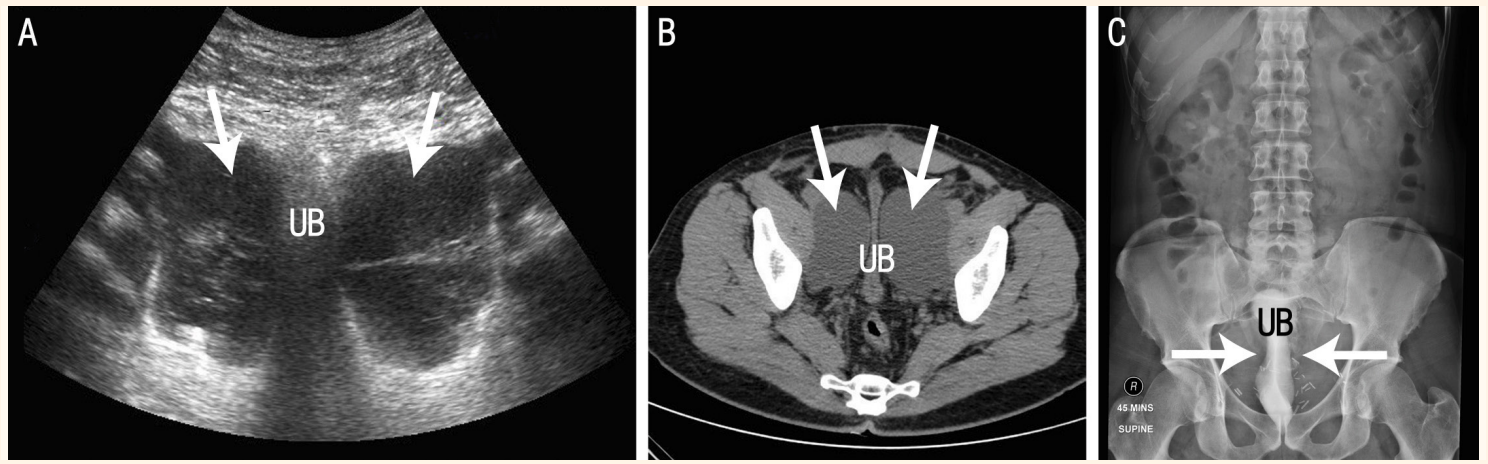

Figure 1: A: Ultrasound image showing large hypoechoic pelvic collections (arrows) with compression on the bladder lumen of a 55-year-old male following an open radical prostatectomy with concomitant pelvic lymph node dissection. B: Axial computed tomography of the bladder revealing lymphoceles (arrows) in the form of bilateral large hypodense fluid attenuation collections along the inner aspect of the iliopsoas muscle. C: An intravenous urogram of the contrastfilled bladder demonstrating the degree of extrinsic compression by the lymphoceles (arrows). Note the bilateralmetallic surgical clips adjacent to the inferior aspect of the bladder.

$U B=$ urinary bladder.

A 55-YeAR-OLD MALE PRESENTED TO THE Accident \& Emergency Department of the Armed Forces Hospital, Muscat, Oman, in 2012 with increased micturition, dysuria, bilateral loin pain and progressive bilateral lower limb swelling. Two months previously, he had undergone an open radical prostatectomy with open pelvic lymph node dissection for an adenocarcinoma with a Gleason score of $7(3+4)$. There was no other relevant prior medical history. On physical examination, the patient was afebrile with normal vital signs. An abdominal examination revealed a $7 \mathrm{~cm}$ vertical healed surgical scar in the midline suprapubic region with lower abdominal tenderness. Mild bilateral pitting pedal oedema was noted. All preliminary routine investigation results were within normal limits. Ultrasonography and non-contrast computed tomography $(\mathrm{CT})$ of the kidney and urinary bladder region revealed two large well-defined cystic lesions in the lower pelvis, along the inner aspect of the iliopsoas muscles. The lesions were compressing the bladder from either side, resulting in a significant narrowing of the bladder lumen [Figures 1A \& B]. The right lesion had a volume of $131 \mathrm{~mL}$, while the left lesion was $193 \mathrm{~mL}$ in volume. Intravenous urography confirmed the extrinsic compression of the bladder, resulting in an hourglass appearance [Figure 1C].

In order to relieve the patient's urinary symptoms, CT-guided percutaneous catheter drainage and aspiration of the cystic collections was performed, which confirmed the diagnosis of large bilateral postoperative pelvic lymphoceles. A six-month follow-up CT scan revealed complete regression of the leftsided lymphocele, while the one on the right side had recurred and required repeated drainage [Figure 2]. During this period, the patient's urinary symptoms and bilateral pedal oedema gradually abated. Subsequently, there was complete resolution of the right-sided lymphocele and the patient recovered fully. 


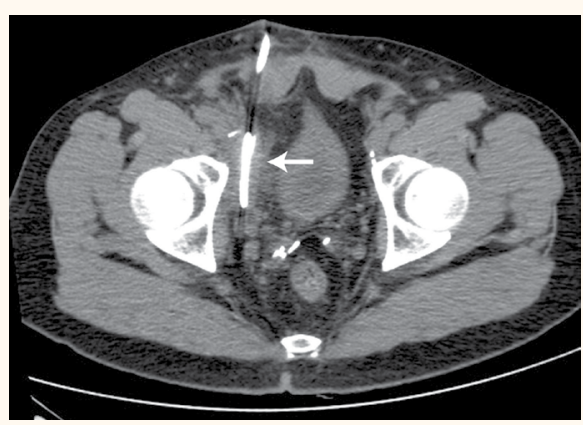

Figure 2: Axial computed tomography scan of a 55-year-old male with large bilateral pelvic lymphoceles six months after percutaneous catheter drainage and aspiration. The left-sided lymphocele showed complete regression, although the lymphocele on the right side had recurred (arrow) and required an in situ drain.

\section{Comment}

A lymphocele is a collection of lymphatic fluid occurring after surgical dissection as a result of inadequate closure of the afferent lymphatic vessels. ${ }^{1}$ Pelvic lymphoceles are a known complication of concomitant pelvic lymph node dissection and radical prostatectomy. ${ }^{2}$ While up to $15 \%$ of patients treated by radical prostatectomy may develop postoperative pelvic lymphoceles, only $2.6 \%$ of these are symptomatic. ${ }^{2}$ Symptomatic patients usually present with pelvic bloating, lower abdominal pain, increased urinary frequency and lower limb oedema, all of which can be attributed to the mass effect of the lymphoceles on the adjacent pelvic organs and veins. ${ }^{3}$

The risk of developing symptomatic lymphoceles is lower after laparoscopic surgery in comparison to open surgery. ${ }^{2}$ In the current case, the patient had undergone open surgery, which likely contributed to the formation of large symptomatic lymphoceles. The possibility of lymphocele formation following a radical prostatectomy should therefore be considered among patients who present with lower abdominal and urinary symptoms. In a retrospective study of 521 patients who had undergone robot-assisted extended pelvic lymph node dissection, Keskin et al. found that only $2.5 \%$ of patients developed symptomatic lymphoceles that required intervention; however, patients with diabetes mellitus had a significantly higher risk of developing symptomatic or infected lymphoceles. ${ }^{4}$
Patients with symptomatic lymphoceles rarely require open surgery; uniloculated lesions are usually managed successfully via simple interventions such as ultrasound or CT-guided percutaneous drainage with or without sclerotherapy, while multiloculated lesions can be treated laparoscopically.,5 According to Gust et al., asymptomatic lymphoceles of less than $100 \mathrm{~mL}$ do not require treatment; however, prophylactic or early interventions should be considered for larger lymphoceles in order to prevent complications like deep vein thrombosis or the formation of pelvic abscesses. ${ }^{1}$ Stolzenburg et al. recommended that peritoneal fenestration be routinely performed after a concomitant radical prostatectomy and pelvic lymph node dissection, as this significantly reduces the incidence of both symptomatic and asymptomatic lymphoceles, without an increase in postoperative morbidity. ${ }^{3}$ This procedure involves the surgical creation of a peritoneal window to drain fluid from the lymphocele into the peritoneal cavity, after which a tongue of omentum is brought down and placed through the window to prevent it from closing.

\section{References}

1. Gust KM, Engel O, Schertl U, Kuefer R, Rinnab L. Clinical significance of postoperative lymphoceles following pelvic lymph node dissection in prostate cancer disease. Nephrourol Mon 2009; 1:94-102.

2. Heers H, Laumeier T, Olbert PJ, Hofmann R, Hegele A. Lymphoceles post-radical retropubic prostatectomy: A retrospective evaluation of epidemiology, risk factors and outcome. Urol Int 2015; 95:400-5. doi: 10.1159/000381463.

3. Stolzenburg JU, Wasserscheid J, Rabenalt R, Do M, Schwalenberg T, McNeill A, et al. Reduction in incidence of lymphocele following extraperitoneal radical prostatectomy and pelvic lymph node dissection by bilateral peritoneal fenestration. World J Urol 2008; 26:581-6. doi: 10.1007/s00345008-0327-3.

4. Keskin MS, Argun ÖB, Öbek C, Tufek I, Tuna MB, Mourmouris P, et al. The incidence and sequela of lymphocele formation after robot-assisted extended pelvic lymph node dissection. BJU Int 2016; 118:127-31. doi: 10.1111/bju.13425.

5. Treiyer A, Haben B, Stark E, Breitling P, Steffens J. Uni- vs. multiloculated pelvic lymphoceles: Differences in the treatment of symptomatic pelvic lymphoceles after open radical retropubic prostatectomy. Int Braz J Urol 2009; 35:164-9. doi: 10.1590/S1677-55382009000200006 